\title{
DOSSIE
}

\section{Hélices, sistemas, ambientes e modelos: os desafios à Sociologia da Inovação}

MARIA LUCIA M ACIEL

\section{Introdução}

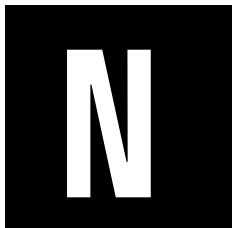

a maioria dos trabalhos que analisam a posição e o potencial da sociologia contemporânea, reconhece-se a dificuldade de entender e enfrentar as transformações por que passa o nosso mundo... e nós mesmos.

Enfrentar, no caso, significa obter o maior proveito possível dos recursos materiais e imateriais que essas transformações oferecem, aperfeiçoando os instrumentos políticos disponíveis para incluir o maior número possível de indivíduos na distribuição dos benefícios das transformações; em outras palavras, o desenvolvimento social e econômico.

Mas, para enfrentar, é preciso primeiro entender. E para entender ou melhor, compreender - é preciso primeiro enfrentar... outro desafio: deixarmos de ser conservadores. Não podemos pretender a compreensão dos atuais processos de mudança social sem avaliar e adequar os nossos instrumentos. Assim como será preciso aperfeiçoar os instrumentos políticos referidos acima, também temos que desenvolver e empregar novas estratégias de conhecimento da nossa realidade, ao mesmo tempo sabendo garimpar o melhor das nossas tradições teóricas.

A revolução científico-tecnológica dosúltimos vinte anos operou mudanças profundas e aceleradas nas formas de produzir e nas relações sociais que as acompanham. 0 objeto primordial da Sociologia, a mudança social, adquire complexidade cada vez maior e desafia os potenciais teóricos e metodológicos da disciplina. Estes processos atuais de mudança po-

* Professora do Departamento de Sociologia da U niversidade de Braślia (UnB) e pesquisadora visitante no Instituto de Economia da Universidade Federal do Rio de Janeiro (UFRJ). 
dem ser sintetizados na expressão "sociedade do conhecimento".

Sabe-se que, hoje, o desenvolvimento depende predominantemente da capacidade de gerar e aplicar produtivamente o conhecimento, condição indispensável da produtividade, da competitividade, mas também do capital social. Também tem sido constatada mundialmente a eficácia das estratégias regionais e municipais de um desenvolvimento sustentado na integração dos diversos agentes sociais e na circulação ampliada do conhecimento e da informação (M aciel, 1997) - baseadas em conceitos como Tripla H élice, Sistemas Locais de Inovação, Sistemas Produtivos Locais, Ambientes de Inovação, Arenas Transepistêmicas ou Modos de produção do conhecimento. A inovação (em seu sentido mais amplo, tecnológico e social) torna-se objeto-chave - tanto para a ciência social quanto para as políticas e estratégias de desenvolvimento.

A compreensão desses processos é condição indispensável para a elaboração e implementação de políticas de inovação conseqüentes e consistentes de médio e longo prazos. No Brasil, já existem alguns grupos que buscam essa compreensão. Assim como na maior parte dos países, aqui o esforço maior tem sido feito por economistas e, em alguns casos, por engenheiros (e.g., IE/U FRJ, DPCT/U nicamp, Coppe/U FRJ). Por outro lado, praticamente inexistem no Brasil estudos sociológicos sobre a relação entre inovação e desenvolvimento social e econômico.

A Ciência Econômica tem dado uma grande contribuição aos estudos sobre a inovação, na medida em que esta envolve processos de produção material e, portanto, depende de um entendimento do papel das empresas no desenvolvimento, inclusive regional, assim como da política econômica e do ambiente macroeconômico de maneira mais ampla.

$M$ as dados dos países mais avançados demonstram que a capacidade inovadora de uma empresa ou de uma nação não depende pura e simplesmente de sua capacidade econômica de investir em novas tecnologias nem da de seus dirigentes para elaborar estratégias econômicas adequadas, e sim da capacidade social, cultural e política de aplicar produtivamente e aproveitar socialmente os recursos - materiais e imateriais - disponíveis.

Se, no estudo de processos de inovação, a sociologia pode construir 
conceitos com alto poder explicativo para as especificidades de ambientes culturais e político-institucionais, constata-se que a maioria das pesquisas sobre inovação e desenvolvimento até agora realizadas no Brasil ainda não satisfaz as necessidades de compreensão e análise de processos de inovação. O bserva-se, nos estudos mais recentes realizados em vários países, que essa nova realidade exige novas perspectivas e estratégias de análise.

\section{Revolução}

A revolução científico-tecnológica das duas últimas décadas gera ao mesmo tempo novas formas de produção da vida material - transformando suas relações - e novas formas de produção do próprio conhecimento (Gibbons, 1994; Schaff, 1995; Castells, 1996). A própria relação entre ciência e tecnologia está modificando-se e se tornando mais estreita, a tal ponto que, por vezes, é difícil distinguir uma da outra, ao mesmo tempo em que ambas estão permeadas de interesses econômicos - como se viu no caso recente do seqüenciamento do genoma humano.

A chamada globalização ${ }^{1}$, que promove a circulação ampliada de informação e conhecimento e, ao mesmo tempo, agrava desigualdades socioeconômicas, difunde e intensifica transformações radicais nas formas de produção da vida material. O u seja, a atual forma de globalização resulta da revolução científico-tecnológica e simultaneamente a difunde com suas conseqüências - pelo mundo.

Com isso, as relações dinâmicas ativadas por essa revolucão científicotecnológica colocam em cena questões e atores sociais até então desconhecidos, redefinem muitos dos tradicionais e tornam superados uns tantos outros.

Existe ainda uma defasagem entre as transformações na base econômica e as formas de organização social e político-institucional. As diversas manifestações da crise atual (desemprego estrutural, desaceleração da produtividade, crise de valores e falta de perspectiva) resultam da incompatibilidade entre as novas tecnologias e formas de produção, de um lado, e

1 A questão das perspectivas conceituais sobre "globalização" não será discutida aqui. O rienta-nos a excelente discussão feita a esse respeito por Cassiolato et allii em Globalização e Inovação Localizada (1999). 
sistemas sociais e organizacionais obsoletos, de outro (Freeman, 1995)2.

Com a diversidade e a complexidade de formas de organização da produção geradas nesse processo de transição, tendem a emergir novas formas de organização social e, portanto, de organização política. Trata-se de um lento processo de restabelecimento de uma coerência orgânica que é dinâmica e provavelmente instável - entre o modo de produção e as relações sociais e políticas que o acompanham.

As mudanças detectadas nos sistemas socioeconômicos mais avançados indicam a passagem de uma sociedade baseada na produção de bens materiais para a sociedade fundada no conhecimento, o que os anglófonos vêm chamando de knowledge societies. Ao mesmo tempo, a reorganização socioeconômica perpassa o próprio modo de produção do conhecimento, que se rearticula e se flexibiliza em dimensões múltiplas tanto internamente quanto nas suas trocas com o ambiente social em que se desenvolve ${ }^{3}$. No contexto do novo paradigma produtivo, tornam-se imprescindíveis a produção/distribuição do conhecimento e a redução das desigualdades sociais, como aspectos reciprocamente necessários e indispensáveis.

Essas transformações exigem articulações dinâmicas entre universidade, empresa e Estado em um processo de inovação que não é só tecnológica, mas também social. As estratégias que se fazem necessárias dependem da capacidade de inovação tecnológica e social - de um país, de uma região, de uma comunidade. Esta capacidade é configurada por condições sociais reunidas no conceito de "ambiente" institucional e cultural (inspirada parcialmente em Porter, 1990), mais do que pela disponibilidade de recursos materiais. As transformações imateriais (Freeman, op. cit.) que se operam tanto na produção material quanto na produção imaterial (intangibles) terminam por trazer no seu bojo a mudança social - daí a possibilidade de desenvolvimento.

Por isso, o conhecimento é valorizado como agente estratégico,

2 É interessante notar que esta análise de Freeman remete ao velho problema da contradição, constatada por M arx em 1859, entre o desenvolvimento das forças produtivas e as relações sociais de produção até que se restabeleça a coerência necessária. 3 Rearticulações descritas em The New Production of Knowledge, de Gibbons, Schwartzman e outros (1994); ver também os conceitos de Triple Helix (Etzkovitz e Leydesdorff, 1997 e 1998) e de arenas transepistêmicas (Knorr-Cetina, 1982). 
não só para a acumulação econômica, mas também para o funcionamento do próprio Estado e da sociedade. Neste sentido, é necessário entender o modo de articulação dos fatores econômicos e intelectuais do desenvolvimento em cada formação social, ou seja, as formas sociais específicas que toma esse modo de articulação numa sociedade determinada.

\section{Conceitos e modelos}

$\mathrm{N}$ a tentativa de entender a atual revolução, especialistas em várias partes do mundo têm elaborado conceitos e modelos de análise diversos, que têm em comum o foco nesta articulação entre conhecimento e produção. Tripla Hélice, Sistemas de Inovação, Diamante de Porter, Ambientes de Inovação, Arenas Transepistêmicas, Sociedade da Informação, Sociedade do Conhecimento, Sociedade em Rede ou Modo 2 de Produção do Conhecimento são alguns exemplos entre os mais difundidos. No entanto constata-se que nossa capacidade de análise continua limitada e que grande parte dos estudos empíricos baseados nesses modelos é insatisfatória e, portanto, frustrante.

Por quê?

Proponho a seguir, como resposta tentativa, um conjunto de três fatores intimamente articulados que parecem estar restringindo a capacidade de análise e explicação destes processos, acompanhados por contrapontos estratégicos que visam a enriquecer e potencializar os estudos no campo da inovação.

Isolamento disciplinar

Conforme já foi sugerido na introdução, observa-se que a maior parte dos estudos sobre inovação é realizada por economistas. Se, por um lado, sua contribuição tem sido relevante do ponto de vista da análise 
tanto de políticas e ambientes macroeconômicos quanto dos microambientes empresariais, por outro, ela raramente integra a percepção de que esses processos variam conforme contextos político-institucionais e socioculturais diversos.

Para que os fatos econômicos sejam explicados não a partir de si próprios como se eles fossem auto-evidentes, mas a partir do ambiente cultural que os contextualiza, o foco econômico tem que estar associado à percepção sociológica de redes de relações simbólicas e sociais refletidas em arranjos políticos e institucionais mais amplos.

O que se constata, no entanto, é uma relativa falta de interesse das Ciências Sociais (e especialmente da Sociologia) pelo estudo dos processos de inovação tecnológica, desenvolvimento de sistemas de inovação, ambientes socioculturais propícios ao surgimento de redes de relações econômicas, articulações diversas entre grandes e pequenas empresas, entre empresa e universidade e outros temas do campo da inovação.

Aqui, talvez mais que em qualquer outro campo de estudo de processos sociais, a interdisciplinaridade torna-se imprescindível. 0 desenvolvimento socioeconômico exige análises e estratégias socioeconômicas. Portanto, é nossa convicção que os processos de inovação e sua relação com o desenvolvimento regional estão a exigir uma capacidade de análise que seja efetivamente interdisciplinar, integrando as teorias e as metodologias da Economia e das Ciências Sociais.

U ma tentativa neste sentido vem sendo feita em anos recentes com a abordagem da Sociologia Econômica, inaugurada e divulgada por sociólogos como Mark Granovetter (1992) e Richard Swedberg (1992, 1998) e incorporada como Grupo de Trabalho na Associação Internacional de Sociologia (AIS/ISA). Os trabalhos desenvolvidos nesta linha, insistindo no conceito de embeddedness ${ }^{4}$, procuram mostrar como contextos socioculturais moldam estratégias e soluções no campo econômico ${ }^{5}$. Mas 
essa linha de pensamento ainda precisa ser mais desenvolvida, superando a fase inicial de "afirmação de identidade" para desenvolver uma elaboração teórico-metodológica com forte poder explicativo para sustentar análises empíricas mais variadas.

Isolamento do objeto

Este problema é praticamente indissociável do primeiro, embora apresente características próprias. O s limites estreitos do foco na produtividade da empresa, na política industrial, no desemprego, no lucro ou na competitividade, por exemplo, restringem a capacidade de compreensão dos processos de transformação social e reduzem a competência para elaboração de estratégias de desenvolvimento.

0 poder explicativo aumenta na medida em que se alarga o foco e se expande a abrangência dos instrumentos de análise. A complexidade proposta por Morin (1982) como princípio metodológico pode ser um instrumento adequado a esses objetos de estudo multifacetadose multiarticulados.

Segundo M orin, o mundo, ind efinido e imprevisível, manifesta-se ao observador como obscuridade, incerteza, ambigüidade, paradoxo, contradição; surge de todos os lados a necessidade de um princípio explicativo mais rico do que aquele que privilegiava o materializável, definível, mensurável. Não se propõe com isso uma mera medida de complicação, mas um princípio metodológico pelo qual os objetos dependem de outros objetos, as relações de outras relações. Portanto, pensar os processos mais que os resultados, as relações mais que as coisas. Logo, weberianamente, privilegiar a compreensão acima da explicação.

Isolamento "histórico-teórico"

Nos estudos sobre inovação, revolução científico-tecnológica e suas conseqüências, sistemas e redes de inovação, relação pesquisa-produção, etc. tem sido freqüente o impulso de propor novos "modelos" teóricos, às 
vezes acompanhados de fórmulas matemáticas ou gráficos esquemáticos para explicar relações de causa e efeito que não levam em conta a complexidade do tema tratado. Na grande maioria, esses "modelos'" estão soltos isolados - no espaço e no tempo, não levando em consideração todo um arcabouço teórico acumulado ao longo da história e que contém insights preciosos para o entendimento dos processos de transformação atuais.

O s clássicos fundadores da Sociologia legaram-nos a matéria prima de que precisamos para essa empreitada. Não se trata, nos limites deste texto, de esmiuçar teorias nem de "tomar posição" quanto a uma ou outra. Lembro apenas, para citar alguns exemplos, a elaboração de Marx sobre o desenvolvimento dasforças produtivas e o conceito weberiano de "afinidade eletiva" que, postulando um tipo especial de associação e relação causal entre as diferentes dimensões sociais, permite perceber - nos processos de inovação, por exemplo - a diversidade histórico-cultural de soluções sociais para questões relativas ao desenvolvimento econômico. A retomada das teorias clássicas é, provavelmente, a estratégia mais profícua para uma análise inovadora dos atuais processos de mudança social.

Em resumo, os dois principais desafiosà Sociologia hoje estão lançados:

- nas fronteiras interdisciplinares da Sociologia e

- no poder explicativo das teorias clássicas para as questões contemporâneas.

\section{Racionalidades do desenvolvimento}

Se retomarmos agora, em síntese, a descrição das mudanças sociais recentes e os problemas conceituais para sua análise, podemos desenvolver uma ilustração da relevância das teorias clássicas para o estudo de questões atuais.

Ao descrever a revolução científico-tecnológica do nosso tempo, vimos que há uma estreita relação entre conhecimento, inovação e desenvolvimento. Este depende, hoje, da capacidade de inovação tecnológica e 
social. Ao mesmo tempo, não há inovação sem produção, acumulação e distribuição do conhecimento. Pensando em termos de uma "Sociologia Econômica" que não estuda um objeto isolado numa disciplina isolada, mas sim uma complexa teia de relações e processos indissociáveis, a idéia de que 0 ambiente cultural configura o modo de articulação dos fatores intelectuais e econômicos disponíveis e articulados para a inovação remete à idéia weberiana de "afinidades eletivas", recuperando a tradição clássica para os estudos da nossa contemporaneidade.

Histórias recentes de desenvolvimento têm revelado capacidades inovadoras inesperadas não só no Japão e na Itália nas décadas de 70 e 80 (Maciel, 1996), mas também, mais recentemente, na China, em Portugal e na Irlanda inspirando um retorno a W eber e, eventualmente, contribuindo para uma avaliação mais precisa das possibilidades e limites que se apresentam a países em desenvolvimento. O s indicadores habituais de desenvolvimento, situados na moldura da "racionalidade instrumental" weberiana não explicam essas histórias de sucesso, o que não significa dizer que Weber pode ter errado em sua avaliação da afinidade eletiva entre a ética protestante e o espírito do capitalismo. M uito pelo contrário.

Se, por um lado, W eber negou a possibilidade de desenvolvimento capitalista em países católicos e nos orientais, por outro, a atual revolução indica transformações no modo de desenvolvimento capitalista: o capitalismo não é mais o mesmo do tempo de Weber. 0 que se sugere aqui é que essas transformações no capitalismo contemporâneo podem estar encontrando afinidades com outras "éticas" e racionalidades (Maciel, 1999). Esta hipótese tem implicações claras para os países em desenvolvimento.

A idéia de que os países protestantes anglo-saxões são "por natureza" mais eficientes no desenvolvimento capitalista racional está difundida em várias regiões "periféricas" do mundo, produzindo uma espécie de "complexo de inferioridade" - ou pior, uma resignação tácita - em face das duras realidades do subdesenvolvimento ou do desenvolvimento dependente, das relações econômicas internacionais e dos obstáculos enfrentados para mudar essas realidades. 
M as os critérios de "desempenho" vêm mudando junto com as transformações na organização da produção. A "repressão de elementos afetivos e sentimentais da personalidade em nome do sucesso" da empresa lucrativa (Souza, 1999) não é mais necessariamente um fator de bom desempenho no capitalismo contemporâneo. Valores como confiança e lealdade são hoje reiteradamente considerados fundamentais no novo paradigma tecno-econômico, e a sociedade relacional parece estar mais sintonizada com os tempos, os espaços e as articulações de sistemas produtivos em transformação. Em muitos casos, observa-se que as habilidades desenvolvidas ao longo de séculos para enfrentar dificuldades extraordinárias resultam na capacidade de dar respostas ágeis e flexíveis aos desafios do mundo contemporâneo e são consideradas "vantagens competitivas" na economia contemporânea, ao mesmo tempo em que se considera o comunitarismo como fator positivo na construção de uma democracia participativa.

A questão que se pretende destacar aqui é que não há um único "modelo" de desenvolvimento a ser seguido, seja ele japonês, italiano ou qualquer outro, e sim que as especificidades culturais indicam os caminhos e estratégias de cada sociedade. A volta aos sociólogos clássicos no estudo da economia contemporânea, como também preconizam Granovetter, Swedberg e alguns outros, enriquece os nossos esforços analíticos.

\section{Referências bibliográficas}

CASSIO LATO, J.E. e LASTRES, H.M.M., orgs. Globalização e inovação localizada. Brasília: Ibict/MCT, 1999.

CASTELLS, M. The rise of the network society. O xford: Blackwell, 1996.

DO W BO R, L. Governabilidade e descentralização. Suplemento especial do Jornal da Ciência Hoje no 298, 1994.

ED Q UIST, C. Systems of innovation: technologies, institutions and organizations. London: Pinter, 1997. 
ETZKO W ITZ, H. e LEYDESD O RFF, L., orgs. Special issue on science policy dimensions of the triple helix of university/industry/government relations. SPP 24(1), 1997.

ETZKO W ITZ, H. e LEYDESD O RFF. The triple helix as a model for innovation studies. SPP 25(3), 1998.

FIGUEIRED O, V. Produção social da tecnologia. São Paulo: EPU, 1989.

FREEMAN, C. Innovation in a new context. STI Review 15, OCDE, 1995.

GIBBONS, M. et alli. The new production of knowledge. London: Sage, 1994.

GRANOVETTER, M. Economic action and social structure: the problem of embeddedness. In: Granovetter e Swedberg (orgs.) The Sociology of economic Life. Boulder. Colorado: Westview Press, 1992.

KNO RR-CETINA, K. Scientific communities or transepistemic arenas of research? A critique of quasi-economic models of science. Social Studies of Science, vol.12, 1982.

Maciel, M.L. 0 milagre italiano: caos, crise e criatividade. Rio de Janeiro: Relume Dumará/Brasília: Paralelo 15, 1996.

MACIEL, M.L. Transformações sociais, conhecimento e descentralização. Trabalho apresentado no VIII Congresso da Sociedade Brasileira de Sociologia - SBS. Brasília: UnB, 1997.

M ACIEL, M.L. Racionalidades do capitalismo contemporâneo. In: SO UZA, J. (org.) O malandro e o protestante. Brasília: Editora UnB, 1999.

MORIN, E. Science avec conscience. Paris: Fayard, 1982.

NELSO N, R., org. National innovation systems. New York: Oxford University Press, 1993. PIORE, M. e SABEL, C. The second industrial divide: possibilities for prosperity. New York: Basic Books, 1984.

PORTER, M. The competitive advantage of nations. New York: Free Press, 1990.

PUTNAM, R. Making democracy work. Princeton, Mass.: Princeton University Press, 1993.

SCH AFF, A. A sociedade informática. São Paulo: Unesp/Brasiliense, 1995.

SO UZA, J., org. 0 malandro e o protestante. Brasília: Editora UnB, 1999.

STEHR, N. Knowledge societies. London: Sage, 1994. 
SWEDBERG, R. Max Weber and the idea of economic society. Princeton, New Jersey: Princeton University Press, 1998.

W AND ERLEY, F. Pequenos negócios, industrialização local e redes de relações econômicas: uma revisão bibliográfica em Sociologia Econômica. BIB 48, 1999.

WEBER, M. Economía y sociedad. México: Fondo de Cultura, 1969.

WEBER, M. A ética protestante e o espírito do capitalismo. São Paulo: Pioneira, 1985.

\section{Resumo}

A revolução científico-tecnológica dos últimos vinte anos operou mudanças profundas e aceleradas nas formas de produzir e nas relações sociais que as acompanham. 0 objeto primordial da Sociologia, a mudança social, adquire complexidade cada vez maior e desafia os potenciais teóricos e metodológicos da disciplina. Esses processos atuais de mudança podem ser sintetizados na expressão "sociedade do conhecimento". A inovação (em seu sentido mais amplo, tecnológico e social) torna-se objeto-chave - tanto para a ciência social quanto para as políticas e estratégias de desenvolvimento. Se no estudo de processos de inovação a sociologia pode construir conceitos com alto poder explicativo para as especificidades de ambientes culturais e político-institucionais, constata-se que a maioria das pesquisas sobre inovação e desenvolvimento até agora realizadas no Brasil ainda não satisfaz as necessidades de compreensão e análise de processos de inovação. Este artigo expõe um conjunto de três fatores intimamente articulados que parecem estar restringindo a capacidade de análise e explicação desses processos, acompanhados por contrapontos estratégicos que visam a enriquecer e potencializar os estudos no campo da inovação.

Palavras-chave: Teoria sociológica, inovação, sociedade do conhecimento, interdisciplinaridade. 